\title{
Water Distribution Mapping in Polymer Electrolyte Fuel Cells using Lock-In Thermography
}

\author{
L. Rasha ${ }^{1}$, J.I.S. Cho ${ }^{1}$, T.P. Neville ${ }^{1}$, A. Corredera ${ }^{1}$, P.R. Shearing ${ }^{1}$ and D.J.L. Brett ${ }^{1 *}$ \\ ${ }^{1}$ Electrochemical Innovation Lab, Department of Chemical Engineering, UCL, London, UK, WC1E 7JE \\ * Author to whom correspondence should be addressed \\ Tel.: +44(0)2076793310 \\ Web: https://www.ucl.ac.uk/electrochemical-innovation-lab \\ Email: d.brett@ucl.ac.uk
}

\begin{abstract}
Effective water management in polymer electrolyte fuel cells (PEFCs) is essential to achieving optimal performance. Mapping the water distribution is therefore a useful tool for understanding operation and designing new components. One of the most powerful ways of visualising water distribution is through neutron imaging. However, this has limitations in terms of expense, accessibility and the ability to conduct representative operando experiments in a neutron beam line. Here, a simple, cost-effective, lab-based, non-invasive water visualisation tool is presented that allows the effect of operating conditions to be assessed in operando. The approach applies lock-in thermography, whereby a controlled sinusoidal heat pulse on one side of a fuel cell (here using a printed circuit board arrangement), is applied using a Peltier device, and the temperature perturbation on the other side of the fuel cell is monitored using a thermal imaging camera. By 'locking in' to the frequency of the imposed heat stimulus, it is possible to observe water build-up within the cell by monitoring the phase shift between heat pulse and measured temperature. This work validates the use of the lock-in thermography technique by mapping the water distribution under different current densities and under dry and humidified conditions.
\end{abstract}




\section{Keywords}

Lock-in thermography; Thermal imaging; Peltier modules; Thermoelectric modules; Water mapping; Printed circuit board.

\section{Introduction}

Effective water management is key to ensuring good performance and durability for polymer electrolyte fuel cells (PEFCs) [1, 2]. Sufficient water is required for proton conduction in the electrolyte but too much water can impede reactant access to the electrodes and result in 'flooding'. This can be caused as a result of low operational temperatures, over humidification, non-uniform pressure and flow distribution characteristics [3-5]. Conversely, electrolyte dehydration can occur due to over-heating or high flow rates of insufficiently humidified reactant gas [6-8]. Distribution of water in a cell can be highly heterogeneous, with significant differences between areas under the land and channels and along the flow-field channel [9-11]. The external humidification of inlet gases is typically achieved using water columns or wet porous membranes $[12,13]$, which adds considerable sub-system volume. The level of humidification can be controlled by heating both the PEFC and inlet gases, further augmenting parasitic loads and system complexity. Dry and non-heated inlet gas operation would remove these concerns and is commonly utilised in open-cathode systems for low-power applications [14]. Although, it is generally found that the overall performance suffers by up to $40 \%$ due to a lack of humidification $[8,15]$. Further, factors such as manufacturing alignment, flow-field design, mechanical compression, gas diffusion layer (GDL) composition, operating conditions and cell cooling strategies substantially affect water distribution and it will change significantly depending on the current drawn from the cell.

In-situ diagnostic techniques that can map the water distribution during fuel cell operation are a powerful design and optimisation tool. X-ray radiography and tomography have been used to obtain high spatial resolutions down to $\sim 1 \mu \mathrm{m}$ with typical exposure times of $1 \mathrm{~s}$ to map water content within membrane electrode assemblies (MEAs) and flow-field channels [16-19]. Neutron radiography and tomography is highly sensitive to water in operating fuel cells and has been used extensively to investigate operational parameters $[9,20]$, cell designs [21], cold- 
starts [22, 23] and stacks [24, 25] at high resolutions in both through-plane [26] and in-plane orientations $[22,27]$. Raman spectroscopy has resolutions of 25-50 $\mu \mathrm{m}$ and has been employed to investigate membrane swelling [28]. Optical techniques have also been used to map water distribution by using transparent windows in the bipolar plates to observe water droplets within the cell [29]. All these techniques require either specialist equipment access, which limits available experimental time, or cell modification that can render them 'artificial' or not representative of technological systems.

Thermal imaging cameras are widely available and have been applied extensively to the study of electrochemical power systems [30]. Temporal thermal maps of the object surface (thermograms) are produced using false-colour images, to show external temperature associated with internal heat generation processes [31].

Lock-in thermography is a non-invasive, non-destructive diagnostic technique that has been utilised in the aeronautical [32, 33], solar panel [34] and electronics field [35-37] to image subsurface defects and material fatigue. It measures changes in the surface temperature to an imposed external thermal stimulation with a thermal imaging camera. Its rapid inspection of large areas and use of lab-based equipment renders it useful for those requiring information about a sample's internal structure. The sensitivity of lock-in compared to other thermal imaging approaches is improved due to the averaging nature of the technique and is emissivity independent [38].

Variations in the lock-in thermography approach have been applied to electrochemical devices. Robinson et al. imaged new and aged Li-ion pouch cells by periodically pulsing the current and were able to detect cracks and gas pockets [39]. Electro-thermal impedance spectroscopy (ETIS) was developed by Engebretsen et al., the first reported use of lock-in thermography on a PEFC single cell, to pinpoint and visualise the location of heat generation within the cell [40]. A periodic electrical stimulus was induced during operation, thus altering the rate of heat generation in the cell due to the altered rate of electrochemical reaction. However, there has yet to be a report of the application of lock-in thermography whereby an external thermal stimulation is used to interrogate internal structural/compositional factors in electrochemical systems. As water build-up within a fuel cell will act to change the thermal propagation 
properties, it can be expected that this will lead to a phase shift in the lock-in signal and thus act as a means of mapping internal water distribution.

A printed circuit board (PCB) fuel cell is used in this study, akin to those being commercially developed by the likes of Bramble Energy (UK) [41]. The approach has the benefit of lowcost, ease of manufacture, no need for bulky end plates and flexibility in terms of the shape formed. However, the approach is equally applicable to the range of PEFC architectures and indeed the broader stable of fuel cell types.

\subsection{Theory of Lock-In Thermography}

Lock-in thermography utilises differing thermal properties of matter to detect internal structures (such a defects) or material change in objects of interest. An external source of heat is required, in this study a Peltier module is used, to generate a sinusoidal thermal excitation. This heat 'wave' propagates through the object via. conduction and is detected as a timevarying temperature signal of the same frequency as the stimulation, using a thermal imaging camera [42]. The phase shift between the excitation signal (input perturbation signal) and the detected thermal response (output measurement signal) is dependent on the thermal properties of the cell materials (Figure 1). An excitation signal applied across a single material would yield an output signal with uniform phase delay across the plane of interest. In the case of a PEFC, the presence of different components such as flow-fields and water will locally alter the phase shifts and allow internal mapping. 

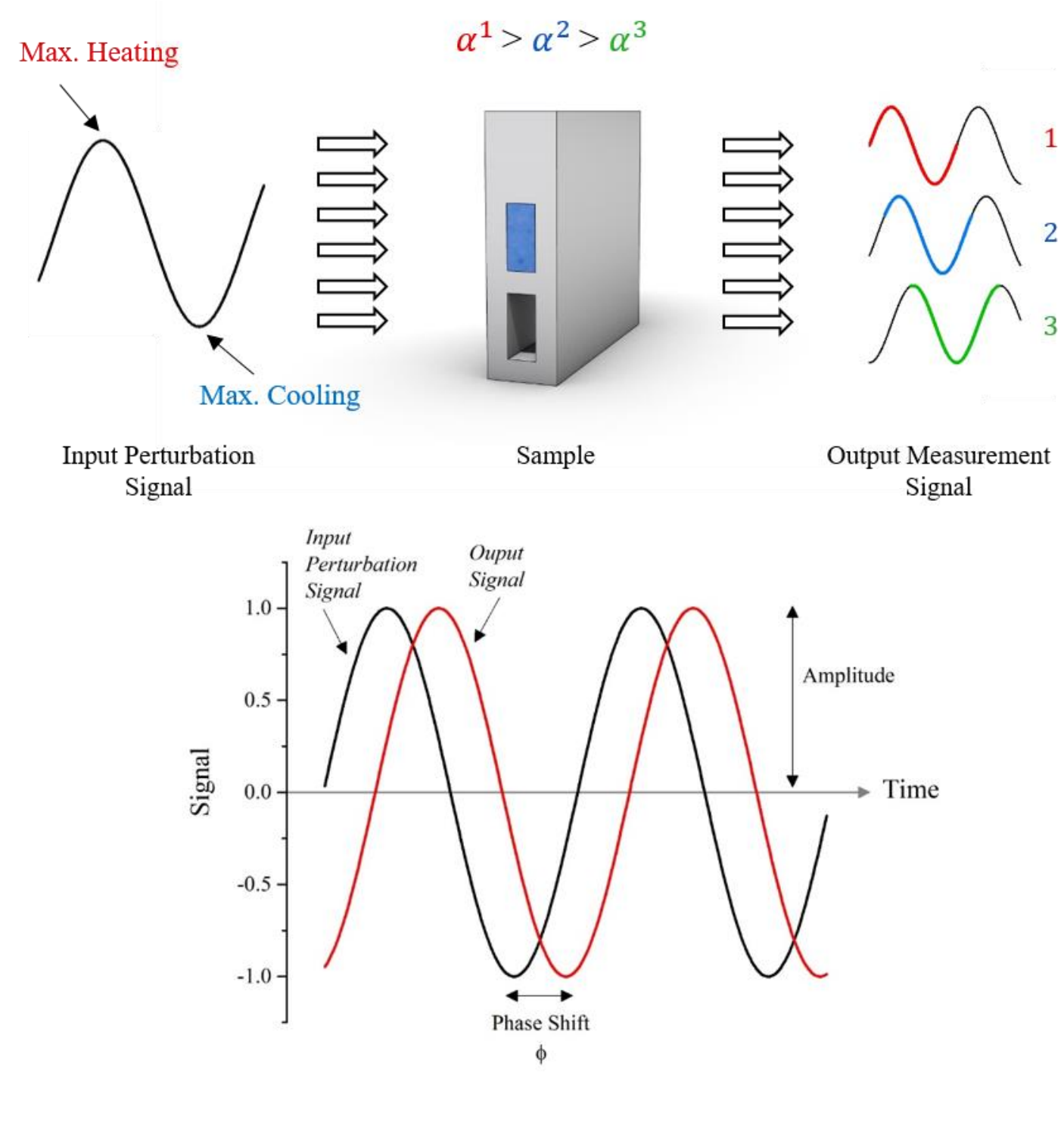

Figure 1: Annotation of the phase shift seen through surface temperature fluctuations to the initial excitation due to differing material thermal diffusivities $(\alpha)$, represented by the three colours. In the case of a PEFC, the red wave (1) represents the cell body if it were made of metal, which is the area outside the region of interest. Blue (2) and green (3) is the water and air inside the flow-field, respectively.

Thermal cameras with lock-in capability (or suitable post processing) filter each pixel and by comparing the amplitude and phase delays of the output signal to the initial perturbation, ampligrams and phase shift images are produced. For this study, phase shift images are used to map the water distribution, as they are less sensitive to non-uniform heating from the Peltier 
module, surface emissivity and environmental reflections which are typically problematic for steady-state thermography [38, 43, 44].

Evaluating different depths within a fuel cell can be theoretically achieved by varying the lockin frequencies. Propagating thermal waves can only travel a certain material depth before its signal is dampened due to the diffusive process of heat conduction [45], and this signal reduction is dependent on the excitation frequency and the energy carried by the excitation [43, $44,46]$. Equation 1 is used to calculate a rough imaging penetration depth based on the thermal properties of the sample. The lower the excitation frequency, (i.e. longer perturbation period), the further the depth of imaging from the surface. Thus, the material structure can be analysed by 'slices' with varying modulation frequency [47]. Commonly, the lock-in thermography technique simultaneously perturbs and images the sample from the same surface; however, in this approach, a heating/cooling source perturbs the reverse side of the sample and the opposite side is imaged in so-called transmission lock-in mode. The Supplementary Information provided demonstrates the depth imaging capability of transmission lock-in thermography using a 'dummy' structure.

$\mu(m)=\sqrt{\frac{k}{\rho c_{p} \pi f}}$

Equation 1

Where $k\left(\mathrm{~W} \mathrm{~m}^{-1} \mathrm{~K}^{-1}\right)$ is the thermal conductivity, $\rho\left(\mathrm{kg} \mathrm{m}^{-3}\right)$ is the specific density, $c_{p}\left(\mathrm{~J} \mathrm{~kg}^{-1}\right.$ $\left.\mathrm{K}^{-1}\right)$ is the specific heat capacity and $f\left(\mathrm{~s}^{-1}\right)$ is the lock-in frequency. Readers are directed to Breitenstein and Lagenkamp [48] for further explanation of the lock-in technique.

\section{Experimental and Methodology}

\subsection{Fuel Cell Assembly}

The PCB fuel cell was constructed from flame-retarded plastic layers (FR4, ZOT) either with or without copper layers. An active area of $9 \mathrm{~cm}^{2}$ was chosen for this study as it provided a suitable area to image water production and effectively heat/cool with a Peltier module. The $0.2 \mathrm{~mm}$ thick FR4 endplates were used to seal the back of each flow-field plate. $0.5 \mathrm{~mm}$ deep and $1.1 \mathrm{~mm}$ wide double-serpentine flow channels were milled into $1 \mathrm{~mm}$ thick FR4 plates with copper layers for the anode and cathode flow-fields, constructed in a counter-flow 
configuration, which promotes a more homogeneous membrane hydration [49]. $0.5 \mathrm{~mm}$ deep inlet and outlet manifolds were milled on the back-side of each flow-field to connect the flow channels to the main gas supply. A front view of the cathode plate is shown in Figure 2(a). The copper layer was nickel and gold coated using electro-plating to a thickness of $5 \mu \mathrm{m}$ to improve corrosion resistance. The coating procedure is outlined in greater detail in $[50,51]$. Epoxy resin 'prepreg' (Arlon EMD) sheets were used to fuse the layers together and provide suitable compression to the MEA. Once cured, each sheet of prepreg layer measured $70 \mu \mathrm{m}$ in thickness. Prior to hot-pressing, they were kept in a vacuum for 24 hours to remove any moisture and ensure proper bonding.
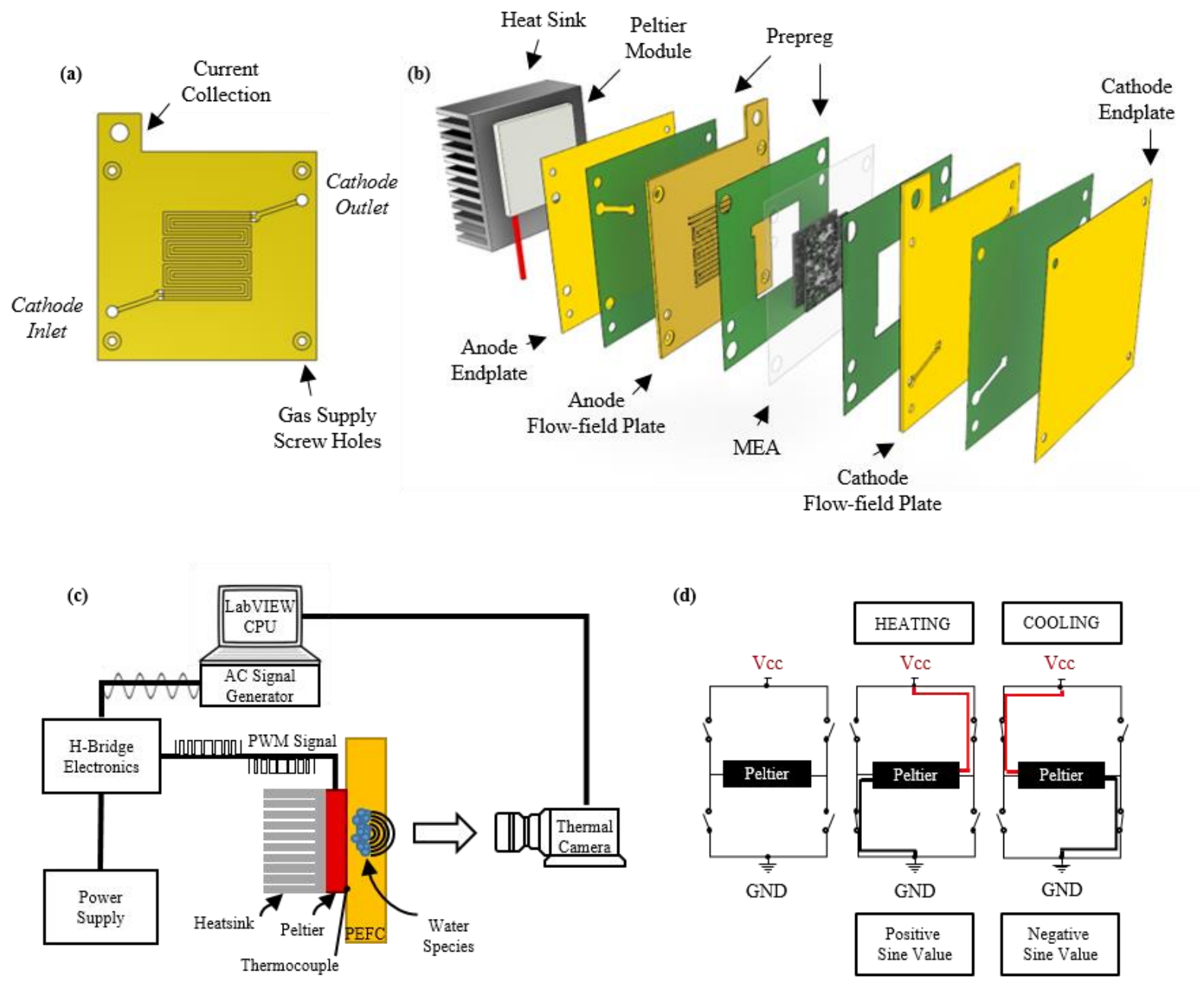

Figure 2: (a) Computer-generated image of the cathode flow-field plate where the manifold is on the back of the plate; (b) 'exploded' view of the fuel cell configuration showing the layers as they would be before hot-pressing. Peltier module is attached to the anode end-plate; (c) experimental setup of the lock-in technique with heat transfer from the Peltier and heat generated by the electrochemical reaction; (d) Hbridge configuration for controlling the Peltier module. 
Both the end-plates and flow-field plates were cut using a CNC machine (Modela MDX-40, Roland) and the prepreg and membrane were stamped out to include the MEA spacing and manifolds using a laser cutter (HPC Laserscript).

The MEA consisted of a $20 \mu \mathrm{m}$ membrane (GORE) and two $9 \mathrm{~cm}^{2}$ gas diffusion electrodes (GDEs) with $0.4 \mathrm{mg} \mathrm{cm}^{-2}$ platinum loadings (HyPlat), placed on either side of the membrane. The fuel cell components were assembled as shown in Figure 2(b), between pieces of woven Teflon fabric (Tygaflor, Saint-Gobain) and placed between two steel hot-pressing plates that provided even compression during heating. Alignment pins were used to prevent the layers from moving. The assembly was evenly hot-pressed (Bungard Elektronik) for 1 hour at $140{ }^{\circ} \mathrm{C}$ and 1.2 bar clamping pressure as dictated by the prepreg curing requirements and the total surface area of compression.

The cell was conditioned galvanostatically on a commercial fuel cell test station (840 Advanced Fuel Cell Test System, Scribner Associates) in through-flow mode. Zero grade gases were supplied by BOC (London, UK) with the following specifications: nitrogen (99.998\% purity), air (99.998\% purity) and hydrogen (99.995\% purity). To condition the MEA, reactant gases at $100 \%$ relative humidity were fed to the system at room temperature and no external heating was applied to the fuel cell. The current density was incrementally ramped up to $1 \mathrm{~A} \mathrm{~cm}^{-2}$ and held for 15 minutes. 10 current sweeps were performed to temperature cycle the MEA. Between each test, the system was purged with $\mathrm{N}_{2}$ to remove as much water and residual $\mathrm{H}_{2}$ from the system. The current interrupt method was performed to observe the membrane Ohmic resistance at a frequency of 10 interrupts per second. Throughout testing, the minimum flow rate was set to $0.1 \mathrm{~L} \mathrm{~min}^{-1}$ for both anode and cathode with stoichiometric ratios of 1.5 and 3 , respectively. The largest cell pressure drop of $4.75 \mathrm{kPa}$ occurs at the highest current density.

\subsection{Lock-In Thermography}

The experimental setup for the lock-in technique is shown in Figure 2(c). The Peltier module was placed on the anode side of the fuel cell and the thermal imaging camera faced the cathode. The other face of the Peltier module was attached to a heat sink with a fan blowing air over it, preventing over-heating of the Peltier module and ensuring thermal stability. A $1 \mathrm{~mm}$ thick 
thermal adhesive tape with a thermal conductivity of $1.6 \mathrm{~W} \mathrm{~m}^{-1} \mathrm{~K}^{-1}$ was placed in between each component to ensure good thermal contact.

LabVIEW (National Instruments) was used to control the hardware of the experiment and data was recorded at $5 \mathrm{~Hz}$. The code generated a sine wave based on the required perturbation frequency, which was converted to a 1-9 V analogue output signal and sent to the thermal imaging camera using a data acquisition board (DAQ, National Instruments). The sine wave was further converted to a pulse-width-modulated (PWM) signal at a $1 \mathrm{~Hz}$ frequency using an analogue-to-digital (ADC) converter as the Peltier module operates with DC current. To alternate the Peltier module from heating to cooling, the polarities of the applied voltage needed to be switched. Thus, an electronic H-bridge illustrated in Figure 2(d), was built using MOFSETs, powered by the pulsed digital output signals from the LabVIEW programme. Between tests, sufficient time was given to ensure thermal equilibrium was established before starting acquisition.

Equation 1 was used to calculate approximate penetration depths. For FR4, the through-plane conductivity is $0.25 \mathrm{~W} \mathrm{~m}^{-1} \mathrm{~K}^{-1}$, specific density is $1360 \mathrm{~kg} \mathrm{~m}^{-3}$ and specific heat capacity is $1500 \mathrm{~J} \mathrm{~kg}^{-1} \mathrm{~K}^{-1}[52,53]$. For the lock-in technique, the perturbation frequency was scanned from 0.02 to $0.07 \mathrm{~Hz}$ for depth analysis from the cathode flow-field to the MEA region, which equated to a rough penetration depth of 0.75 to $1.4 \mathrm{~mm}$ from the surface of the cathode endplate.

The Peltier cooler module (HP-199-1.4-0.8, TE Technology Inc.) was operated at $5 \mathrm{~V}$ using a power supply (QPX1200SP, Aim-TTi) with a square area of $16 \mathrm{~cm}^{2}$, covering the fuel cell active area. The Peltier module was used to provide a heat excitation whilst maintaining the cell temperature within suitable operational limits. The cell was kept around a set point temperature of $40 \pm 7{ }^{\circ} \mathrm{C}$. The current density was limited to $900 \mathrm{~mA} \mathrm{~cm}{ }^{-2}$ due to limitations in Peltier cooling capacity. K-type thermocouples (TC-08, Pico Tech) recorded temperature readings of the endplate in contact with the Peltier module.

The thermal imaging camera $(640 \times 512$ FPA InSb FLIR SC5000MB) recorded thermograms at $25 \mathrm{~Hz}$ using commercially available software (Altair, FLIR ATS) and was calibrated for the expected temperature range $\left(15-80{ }^{\circ} \mathrm{C}\right)$. The Narcissus effect was removed using nonuniformity compensation (NUC). The distance between the camera lens and PEFC surface was 
$7 \mathrm{~cm} .7500$ frames were recorded for each perturbation frequency for an acquisition time of 5 minutes. For the conventional thermogram images, a uniform emissivity of 0.94 was assumed for FR4 material [54]. However, the phase and amplitude images are emissivity independent.

\subsection{Lock-In Data Processing}

The Altair LI software compared each pixel of the surface temperature response to the excitation signal sent to the camera. The analysis was performed in 'E-mode', used for examining thermo-elastic effects and evaluates stresses in the material with a threshold of 0.01 DL (digital level) [55] to obtain the phase images.

The original phase images from the lock-in technique mapped the phase shift between the excitation signal and the detected thermal response. Depending on the excitation signal frequency used, a large range of phase shift values are possible, which makes it difficult to compare results for different conditions. Instead, the average of the phase values of the surrounding bulk FR4 body for each frequency examined was subtracted from the total phase images, as described by Equation 2. The larger the phase difference between the two regions, the improved rate of heat transfer. As liquid water presence in the flow channels will produce smaller phase shift values than the bulk FR4 body, due to a greater thermal diffusivity, the phase difference in Equation 2 will be negative.

$\phi=\phi_{\text {pixel }}-\phi_{F R 4, b o d y}$

Equation 2 


\section{Results and Discussion}

\subsection{Fuel Cell Performance}

Figure 3 shows polarisation curves for the fuel cell operating under dry and humidified conditions.

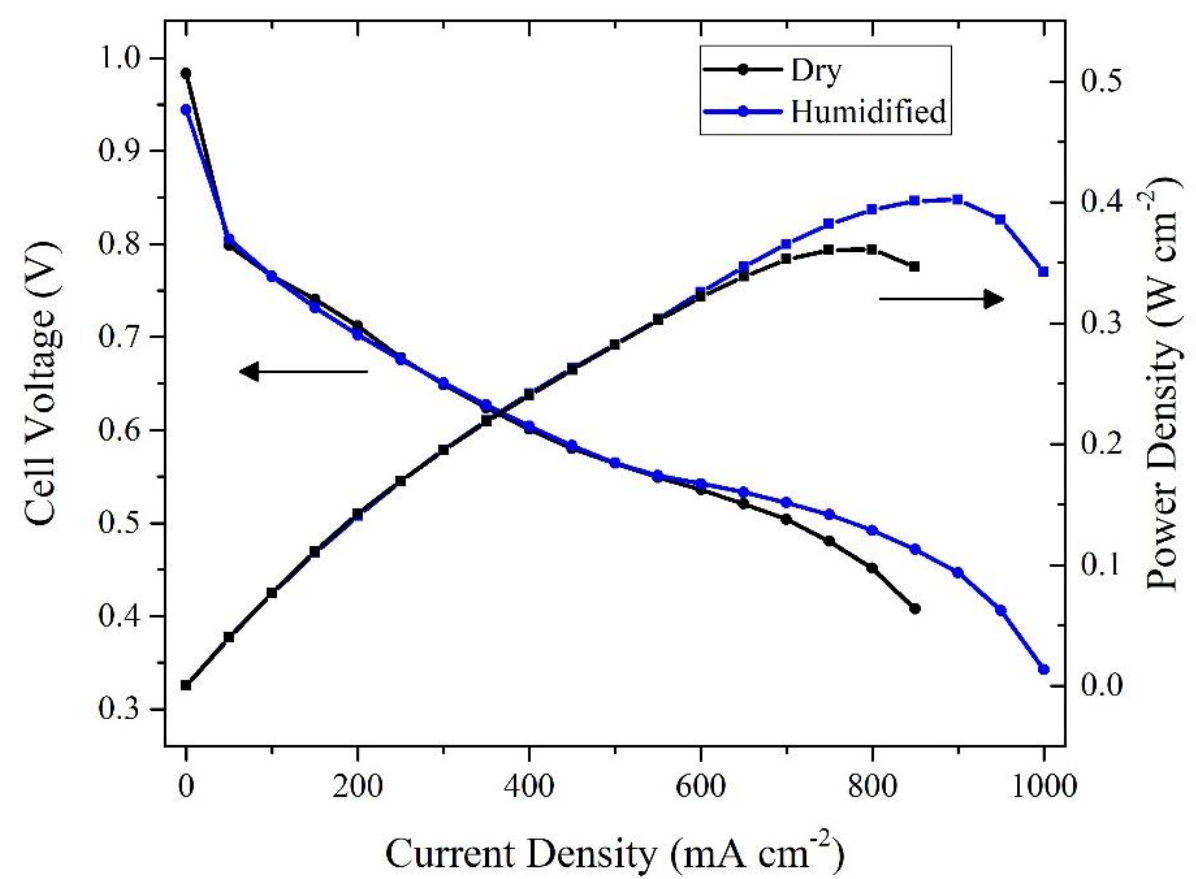

Figure 3: Polarisation and power density curves of the PCB-PEFC under dry and humidified conditions.

Fuel cell operation under dry conditions yielded poorer performance at mid to high current density (>0.6 $\mathrm{A} \mathrm{cm}^{-2}$ ) than under humidified conditions due to membrane dry-out with increasing cell temperature, as indicated by an earlier onset of cell potential drop above 600 $\mathrm{mA} \mathrm{cm}{ }^{-2}$. The membrane Ohmic resistance remained at around $180 \mathrm{~m} \Omega \mathrm{cm}^{2}$ from low to mid current density and started increasing with increasing load, which suggests cell dry-out due to elevated operating temperatures. 


\subsection{Lock-In Signal Validation}

To ensure that the experimental setup was correctly initialised, the lock-in signal generated by the LabVIEW code, the signal sent to the thermal camera and the heating and cooling cycle imposed from the Peltier module and fuel cell interface were synchronised.

Figure A2 in the Supplementary Information shows that the signal produced in the LabVIEW code and received by the thermal camera through the ALTAIR programme are delayed by 0.16 $\mathrm{s}$, which was considered negligible on the time scale of processes in this system. However, the heating perturbation to the fuel cell has a longer intrinsic time delay. Thus, prior to each lockin acquisition, the phase delay difference between the LabVIEW signal and the Peltier response was corrected for, ensuring synchronization of the perturbations for data processing.

\subsection{Comparison of Lock-In Images}

Figure 4 shows the thermogram from steady-state thermal imaging, amplitude image and phase image from operating the cell humidified at $100 \mathrm{~mA} \mathrm{~cm}^{-2}$ with a lock-in frequency of $0.07 \mathrm{~Hz}$. The thermogram shows the effect of heat propagation from the Peltier module through the fuel cell and the consequent thermal diffusion around the active area. The amplitude image shows the dampening of the surface temperature signal to the initial thermal perturbation signal. A higher amplitude ratio is detected in the outlet flow channel compared to the inlet due to an expected greater water presence. However, a more detailed analysis of the water distribution is difficult to obtain and thus amplitude images are more typically used to investigate energy dissipation $[38,56]$. On the other hand, the phase image produced using Equation 2 shows the flow-field and outlet manifold contrasting the surrounding cell body.

Thermogram

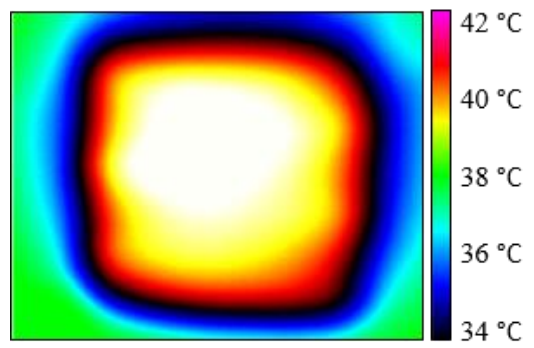

Ampligram

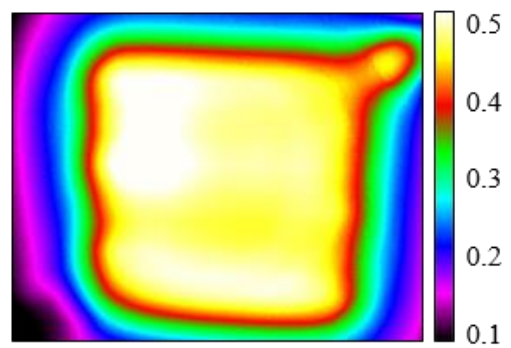

Phase Shift

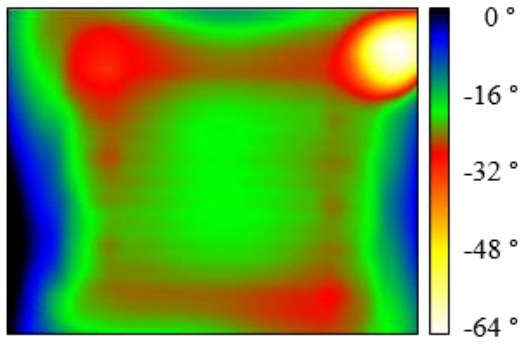

Figure 4: Thermogram of PEFC area of interest, ampligram and phase shift image edited using Equation 2 of humidified operation at $100 \mathrm{~mA} \mathrm{~cm}$ cm $^{-2}$ at a $0.07 \mathrm{~Hz}$ lock-in frequency. 
The clear phase contrast illustrates the practicality of using the phase image to map the internal structure of the fuel cell, as found in other studies requiring sub-surface structure imaging [46, 57]. The channels are discernible from the lands, due to differing thermal conductivities of the internal structure along the heating path. Areas of less thermal resistance are indicated by red/yellow areas in the figure. Additionally, the phase images are more tolerant to non-uniform heating and are emissivity-independent compared to amplitude images [58]. It is predicted that any water presence in the flow-field and manifolds would be detected by the technique, with a smaller phase-shift compared to the lands, due to the higher thermal conductivity of liquid water in the channels $\left(0.607 \mathrm{~W} \mathrm{~m}^{-1} \mathrm{~K}^{-1}\right)$ compared to the land areas $\left(0.25 \mathrm{~W} \mathrm{~m}^{-1} \mathrm{~K}^{-1}\right)[52,59]$.

The spatial resolution of the image is somewhat affected by lateral heat transfer. For FR4, the higher in-plane thermal conductivity $\left(0.6 \mathrm{~W} \mathrm{~m}^{-1} \mathrm{~K}^{-1}\right)$ compared to the through-plane $(0.25 \mathrm{~W}$ $\mathrm{m}^{-1} \mathrm{~K}^{-1}$ ), leads to some blurring of the image around the edges [52]. Additionally, the excellent thermal conductivity of the copper layer and GDL is a disadvantage in this case, as it disrupts the phase change caused by the anode plate and further disperses the heat flow in the lateral direction, rendering the cathode flow-field unfocused.

\subsection{Frequency Dependence Analysis}

Figure 5 shows phase images across the frequency range 0.02 to $0.07 \mathrm{~Hz}$ for humidified operation at $100 \mathrm{~mA} \mathrm{~cm} \mathrm{~cm}^{-2}$. As demonstrated in the Supplementary Information, decreasing frequency probes internal features, with greater penetration depth into the cell from the surface being examined from the camera - the cathode side.

At $0.07 \mathrm{~Hz}$, corresponding to the least penetration depth of approximately $0.75 \mathrm{~mm}$, the lockin signal is 'focused' half-way through the cathode flow-field plate, such that the intersection between the manifolds and flow-field is imaged. The phase shift exhibited by the cathode outlet manifold is much lower than the rest of the flow-field, indicating a larger water presence in the outlet. The manifold is outside the active area, where heat is generated, so it is expected to be cooler than the main flow-field and consequently water is more likely to condense in this region. Also, the wider manifold dimension compared to the flow channel means that exiting gas can bypass the water droplets and not have the same 'flushing out' effect as in the active 
flow-field. As the penetration depth increases towards the MEA with decreasing perturbation frequency, the flow-field becomes less discernible.

The phase shifts at different frequencies for locations corresponding to the channel, land and cathode outlet, as labelled in Figure 5, are shown in Figure 6. With decreasing perturbation frequency, and greater imaging penetration depth, the phase contrast between land and channel widens, indicating improved thermal conductivity in the channel, due to increasing water presence. Conversely, the phase shift in the outlet manifold reduces in magnitude for decreasing perturbation frequency as the 'layering' (depth profiling) technique moves away from the manifold region. 


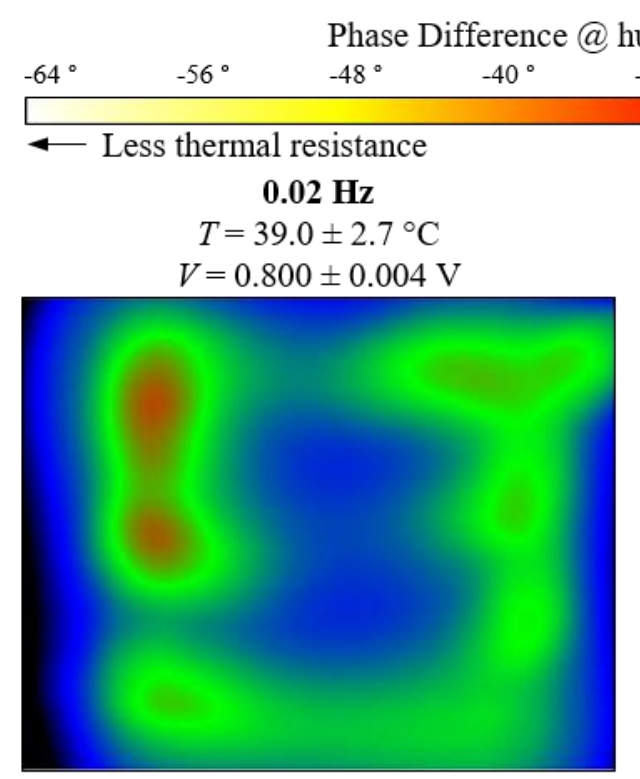

$0.04 \mathrm{~Hz}$

$T=40.9 \pm 1.0^{\circ} \mathrm{C}$

$V=0.795 \pm 0.003 \mathrm{~V}$

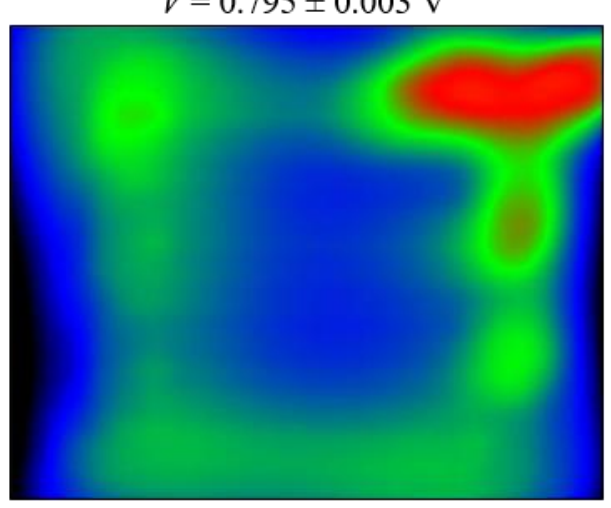

$0.06 \mathrm{~Hz}$

$T=41.7 \pm 0.6{ }^{\circ} \mathrm{C}$

$V=0.792 \pm 0.002 \mathrm{~V}$

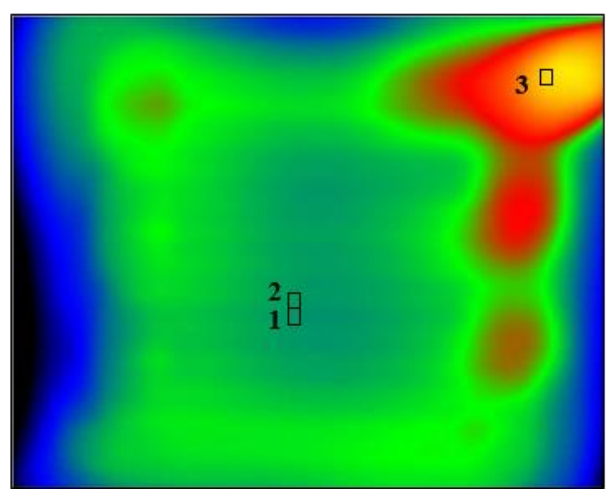

midified $100 \mathrm{~mA} \mathrm{~cm}^{-2}$

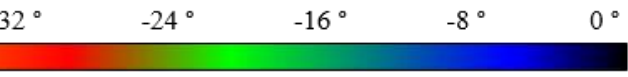

Bulk FR4

$0.03 \mathrm{~Hz}$

$T=40.4 \pm 1.4{ }^{\circ} \mathrm{C}$

$V=0.797 \pm 0.003 \mathrm{~V}$

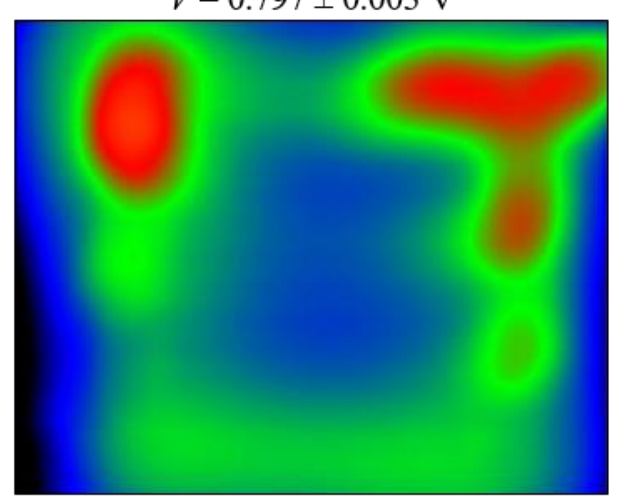

$0.05 \mathrm{~Hz}$

$T=41.2 \pm 0.7^{\circ} \mathrm{C}$

$V=0.792 \pm 0.002 \mathrm{~V}$

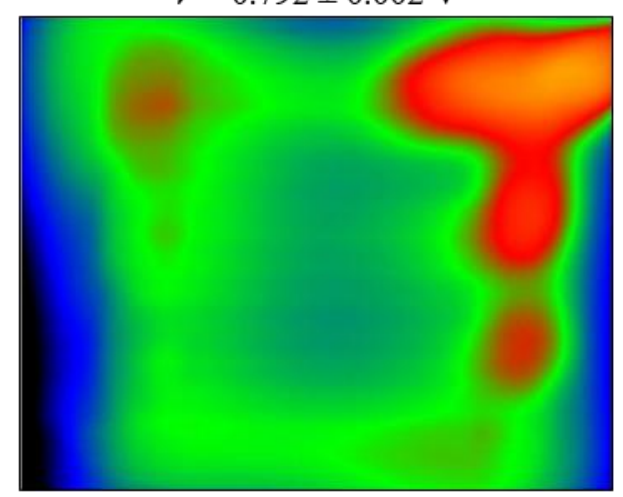

$0.07 \mathrm{~Hz}$

$T=42 \pm 0.5^{\circ} \mathrm{C}$

$V=0.791 \pm 0.002 \mathrm{~V}$

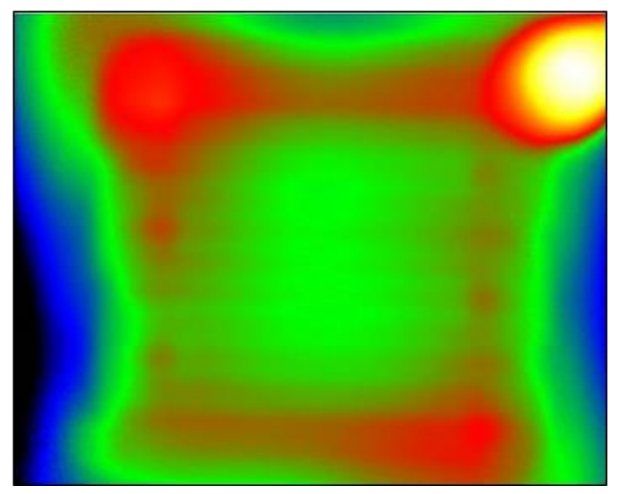

Figure 5: Phase images of humidified operation at $100 \mathrm{~mA} \mathrm{~cm} \mathbf{c m}^{-2}$ at lock-in frequencies 0.02 to $0.07 \mathrm{~Hz}$. Operational temperature and resultant cell voltage oscillations are provided for each experiment. Labelled regions of interest are: 1) land 2) channel and 3) cathode outlet. 


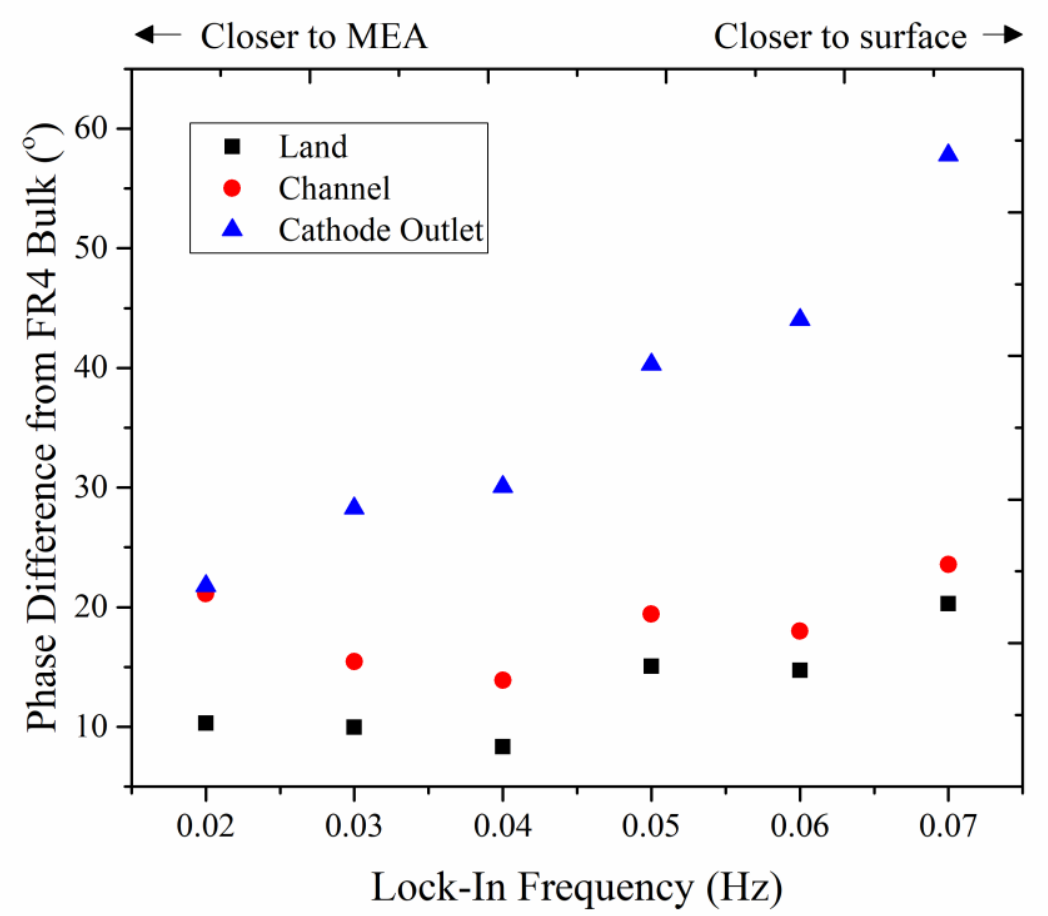

Figure 6: Bode plot of the phase shift for the land, channel and cathode outlet at various lock-in frequencies.

As the Peltier acts to inject (heat) and abstract heat (cool) during the oscillation cycle, there is no net delivery of heat to the cell. Consequently, net temperature change during the experiment is kept to a minimum and lessens the effect on the water dynamics and electrochemistry, with a maximum of $9 \mathrm{mV}$ variation caused by the temperature oscillation.

\subsection{Cathode Humidification and Current Density Variation}

A lock-in frequency of $0.04 \mathrm{~Hz}$ was chosen for the rest of this study to analyse the water distribution at different current densities under dry and humidified operation, as shown in Figure 7. This frequency was selected based on the results from Figure 5, due to a smaller gap in phase shift between the flow-field and outlet without losing the land-channel contrast. The Bode plot in Figure 8 compares the response for the channel, land and cathode outlet. 
Phase Difference@0.04 Hz

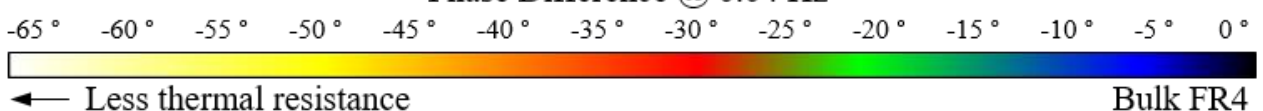

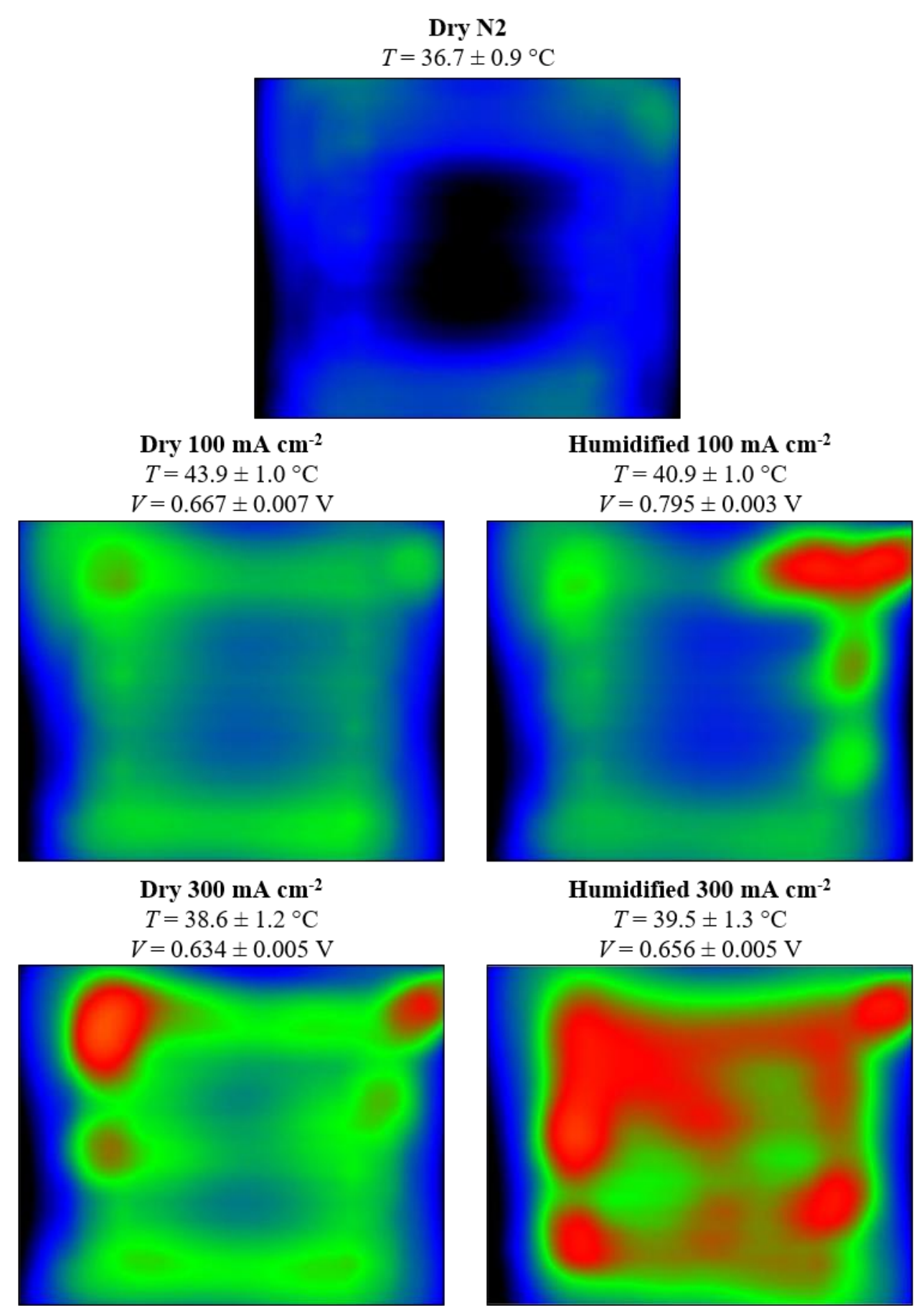




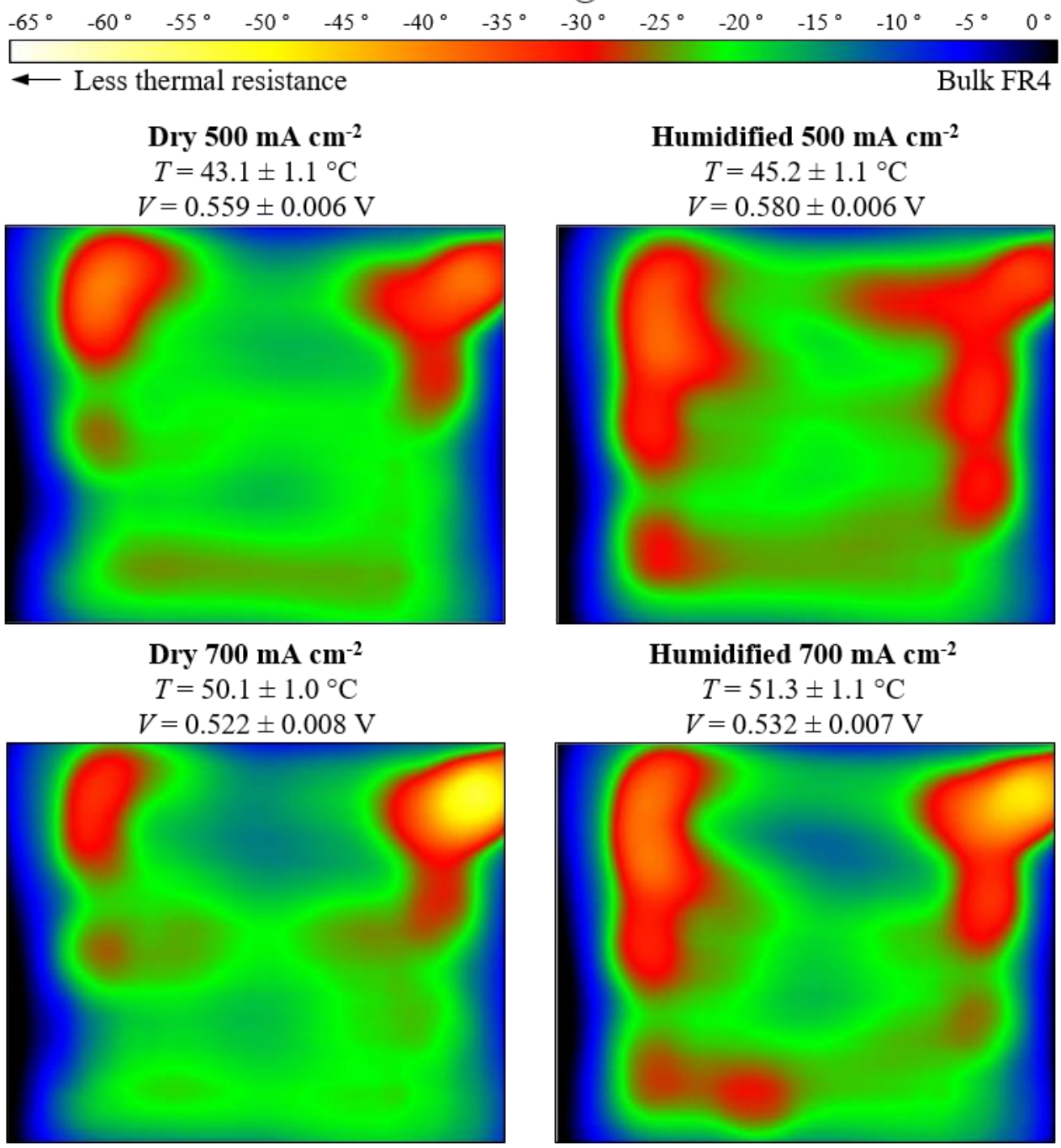

Humidified $900 \mathrm{~mA} \mathrm{~cm} \mathrm{~cm}^{-2}$

$$
\begin{gathered}
T=60.9 \pm 1.0^{\circ} \mathrm{C} \\
V=0.435 \pm 0.009 \mathrm{~V}
\end{gathered}
$$

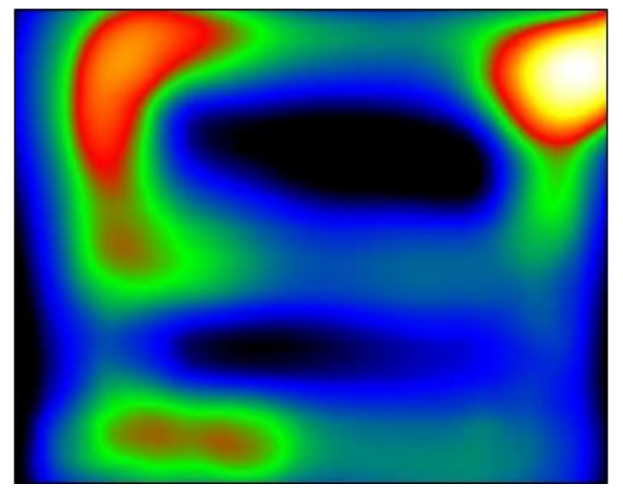

Figure 7: Phase images of a non-operational cell fed with dry, non-heated $\mathbf{N}_{2}$ gas, dry and humidified operation from 100 to $700 \mathrm{~mA} \mathrm{~cm}$-2 and humidified operation at $900 \mathrm{~mA} \mathrm{~cm}$.2. Operational temperature and voltage oscillations are provided for each experiment. 
Galvanostatic operation during lock-in mode exhibited equivalent performance to the conventional polarisation curve in Figure 3. The voltage oscillations under constant load were small $( \pm 0.01 \mathrm{~V})$, due to the small temperature oscillations around the median. Thus, changes in the water distribution as a result of the variation of these parameters is considered to be negligible.

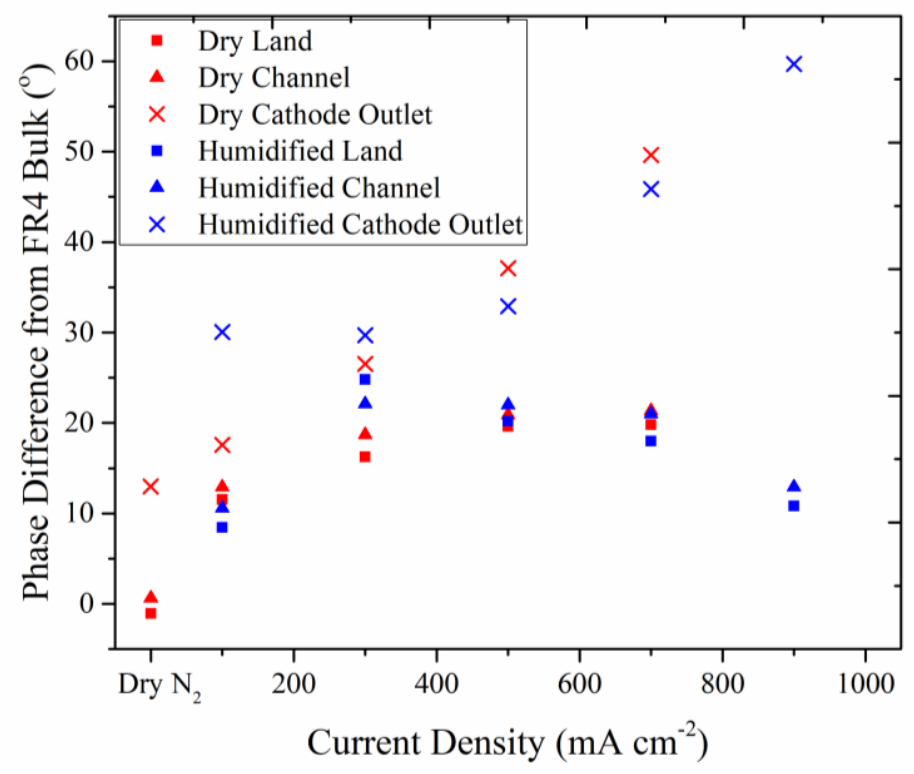

Figure 8: Bode plot of the phase shift for the land, channel and cathode outlet at a lock-in frequency of $0.04 \mathrm{~Hz}$ for varying current densities under dry and humidified conditions.

\subsubsection{Cell Operation}

Comparing the cell operation from 100 to $700 \mathrm{~mA} \mathrm{~cm}^{-2}$, as expected there is greater overall cell water content under humidified gas conditions, with greater pooling in the bends and outlet channels. This corroborates the neutron radiography based findings of Coz et al., which report lower temperatures at the edges of the active area than the centre, especially at higher current densities [60]. Additionally, water accumulation in the bends is common for serpentine configurations due to flow instability induced at corners and decreased pressure drop caused by short-circuiting of gas between adjacent channels [61].

At $700 \mathrm{~mA} \mathrm{~cm}{ }^{-2}$, the cell temperature increases and results in the onset of cell dry-out at the centre of the active area. This is exacerbated under non-humidified conditions, although water 
continues to accumulate in the cathode outlet due to its lower temperature, leading to condensation, as suggested by Figure 8 .

A current density of $900 \mathrm{~mA} \mathrm{~cm}{ }^{-2}$ could not be reached under dry operating conditions due to low voltages caused by excessive cell drying. This is evident in the humidified case which shows that an increase in cell temperature has formed large dry zones which have a marked effect on the cell performance. However, water pooling is still pronounced at the last serpentine bend and outlet channel due to the amount of water produced from the high current operating conditions.

\subsection{Discussion}

The water distribution of a PEFC constructed with FR4 material has been mapped using lockin thermography. The technique works by applying a sinusoidal thermal excitation around a set-point temperature, which in this study was kept at $40{ }^{\circ} \mathrm{C}$ to ensure stable performance during acquisition. However, there is no constraint on this set-point. Indeed, by operating at different temperatures, different flow distributions can be imaged.

The theoretical spatial resolution for this study was $\sim 78 \mu \mathrm{m}$ based on the dimensions of the imaged area and the thermal camera capability. However, the actual resolution was limited by the dampening of the input perturbation signal propagating through the PEFC due to lateral heat transfer, causing a blurring of the flow-field. The surface thermal response captured by the camera can be improved by using more thermally conductive materials, such as the metallic plates used in conventional PEFC designs, as opposed to thermally resistant FR4 plates and thinner plates. Higher perturbation frequencies can thus be utilised for shorter experimental times to capture transient water profiles, as typically employed in other fields of lock-in thermography.

\section{Conclusion}

Lock-in thermography has been successfully used to map water distribution in an operational PEFC. The technique allows different depths within the cell to be probed (through the flow- 
field, down to the MEA) by varying the modulation frequency. The water distribution was mapped successfully under dry and humidified conditions at different current densities. The findings are consistent with results obtained in literature using neutron imaging, showing pooling in the bends of a serpentine flow-field configuration and a greater water content in the outlet compared to the inlet, validating the viability of the technique.

\section{Acknowledgements}

The authors would like to acknowledge funding from the EPSRC (EP/L015277/1, EP/P009050/1, EP/M014371/1, EP/M009394/1, EP/M023508/1, EP/L015749/1, EP/N022971/1) for supporting fuel cell research in the Electrochemical Innovation Lab (EIL) and to the Digital Engineering and Test Centre (APC Spoke) Virtually Connected Hybrid Vehicle (VCHV) project for supporting Lara Rasha. The authors gratefully acknowledge financial support from an EPSRC "Frontier Engineering” Award (EP/K038656/1) and a UCL Faculty of Engineering Sciences Dean's Scholarship for Jason I. S. Cho.

\section{References}

1. Jiao, K. and X. Li, Water transport in polymer electrolyte membrane fuel cells. Progress in Energy and Combustion Science, 2011. 37(3): p. 221-291.

2. $\quad \mathrm{Ji}, \mathrm{M}$. and Z. Wei, A review of water management in polymer electrolyte membrane fuel cells. Energies, 2009. 2(4): p. 1057.

3. $\quad \mathrm{Li}, \mathrm{H}$., et al., A review of water flooding issues in the proton exchange membrane fuel cell. Journal of Power Sources, 2008. 178(1): p. 103-117.

4. $\quad \mathrm{Su}, \mathrm{A}$., et al., Studies on flooding in PEM fuel cell cathode channels. International Journal of Hydrogen Energy, 2006. 31(8): p. 1031-1039.

5. Wu, Y., et al., Effect of serpentine flow-field design on the water management of polymer electrolyte fuel cells: An in-operando neutron radiography study. Journal of Power Sources, 2018. 399: p. 254-263.

6. Knights, S.D., et al., Aging mechanisms and lifetime of PEFC and DMFC. Journal of Power Sources, 2004. 127(1): p. 127-134.

7. Schmittinger, W. and A. Vahidi, A review of the main parameters influencing long-term performance and durability of PEM fuel cells. Journal of Power Sources, 2008. 180(1): p. 1-14.

8. Büchi, F.N. and S. Srinivasan, Operating proton exchange membrane fuel cells without external humidification of the reactant gases: Fundamental aspects. Journal of The Electrochemical Society, 1997. 144(8): p. 2767-2772.

9. Hartnig, C., et al., Combined neutron radiography and locally resolved current density measurements of operating PEM fuel cells. Journal of Power Sources, 2008. 176(2): p. 452-459. 
10. Al-saraireh, F., In-situ investigation of water distribution in polymer electrolyte membrane fuel cells using high-resolution neutron tomography with 6.5 um pixel size Saad. 2018.

11. Mukundan, R. and R.L. Borup, Visualising liquid water in PEM fuel cells using neutron imaging. Fuel Cells, 2009. 9(5): p. 499-505.

12. Hyun, D. and J. Kim, Study of external humidification method in proton exchange membrane fuel cell. Journal of Power Sources, 2004. 126(1): p. 98-103.

13. Kuhn, R., et al., Dynamic fuel cell gas humidification system. International Journal of Hydrogen Energy, 2012. 37(9): p. 7702-7709.

14. Meyer, Q., et al., System-level electro-thermal optimisation of air-cooled open-cathode polymer electrolyte fuel cells: Air blower parasitic load and schemes for dynamic operation. International Journal of Hydrogen Energy, 2015. 40(46): p. 16760-16766.

15. Al-Zeyoudi, H., A.P. Sasmito, and T. Shamim, Performance evaluation of an open-cathode PEM fuel cell stack under ambient conditions: Case study of United Arab Emirates. Energy Conversion and Management, 2015. 105: p. 798-809.

16. Krüger, P., et al., Synchrotron X-ray tomography for investigations of water distribution in polymer electrolyte membrane fuel cells. Journal of Power Sources, 2011. 196(12): p. 5250-5255.

17. Markötter, H., et al., Influence of cracks in the microporous layer on the water distribution in a PEM fuel cell investigated by synchrotron radiography. Electrochemistry Communications, 2013. 34: p. 2224.

18. Zenyuk, I.V., et al., Probing water distribution in compressed fuel-cell gas-diffusion layers using X-ray computed tomography. Electrochemistry Communications, 2015. 53: p. 24-28.

19. Manke, I., et al., Investigation of water evolution and transport in fuel cells with high resolution synchrotron x-ray radiography. Applied Physics Letters, 2007. 90(17): p. 174105.

20. Chen, Y.-S. and H. Peng, Studying the water transport in a proton exchange membrane fuel cell by neutron radiography and relative humidity sensors. Vol. 6. 2009.

21. Alrwashdeh, S.S., et al., Neutron radiographic in operando investigation of water transport in polymer electrolyte membrane fuel cells with channel barriers. Energy Conversion and Management, 2017. 148(Supplement C): p. 604-610.

22. Oberholzer, P., et al., Neutron imaging of isothermal sub-zero degree celsius cold-starts of a polymer electrolyte fuel cell (PEFC). ECS Transactions, 2011. 41(1): p. 363-370.

23. Stahl, P., et al., An Investigation of PEFC Sub-Zero Startup: Influence of Initial Conditions and Residual Water. Fuel Cells, 2017. 17(6): p. 778-785.

24. Markötter, H., et al., Neutron tomographic investigations of water distributions in polymer electrolyte membrane fuel cell stacks. Journal of Power Sources, 2012. 219: p. 120-125.

25. Meyer, Q., et al., The hydro-electro-thermal performance of air-cooled, open-cathode polymer electrolyte fuel cells: Combined localised current density, temperature and water mapping. Electrochimica Acta, 2015. 180: p. 307-315.

26. Owejan, J.P., et al., Water management studies in PEM fuel cells, Part I: Fuel cell design and in situ water distributions. International Journal of Hydrogen Energy, 2009. 34(8): p. 3436-3444.

27. Cho, K.T. and M.M. Mench, Investigation of the role of the micro-porous layer in polymer electrolyte fuel cells with hydrogen deuterium contrast neutron radiography. Physical Chemistry Chemical Physics, 2012. 14(12): p. 4296-4302.

28. Huguet, P., et al., In situ analysis of water management in operating fuel cells by confocal Raman spectroscopy. Electrochemistry Communications, 2011. 13(5): p. 418-422. 
29. Bozorgnezhad, A., et al., The experimental study of water management in the cathode channel of singleserpentine transparent proton exchange membrane fuel cell by direct visualization. International Journal of Hydrogen Energy, 2015. 40(6): p. 2808-2832.

30. Robinson, J., P. Shearing, and D. Brett, Thermal imaging of electrochemical power systems: A review. Journal of Imaging, 2016. 2(1): p. 2.

31. Usamentiaga, R., et al., Infrared thermography for temperature measurement and non-destructive testing. Sensors (Basel), 2014. 14(7): p. 12305-48.

32. Meola, C., et al., Non-destructive evaluation of aerospace materials with lock-in thermography. Engineering Failure Analysis, 2006. 13(3): p. 380-388.

33. Ibarra-Castanedo, C., et al., Inspection of aerospace materials by pulsed thermography, lock-in thermography and vibrothermography: A comparative study. 2007.

34. Breitenstein, O., et al., Lock-in thermography - A universal tool for local analysis of solar cells, in 20th European Photovoltaic Solar Energy Conference. 2005: Barcelona. p. 590-3.

35. Schmidt, C., F. Altmann, and O. Breitenstein, Application of lock-in thermography for failure analysis in integrated circuits using quantitative phase shift analysis. Materials Science and Engineering: B, 2012. 177(15): p. 1261-1267.

36. Huth, S., et al., Lock-in IR-thermography - A novel tool for material and device characterization. Vol. 82-84. 2002.

37. Kijkanjanapaiboon, K., et al., Investigation of dimensional and heat source effects in lock-in thermography applications in semiconductor packages. Vol. 113. 2016.

38. Breitenstein, O., et al., New developments in IR lock-in thermography. 2004.

39. Robinson, J.B., et al., Detection of internal defects in lithium-ion batteries using lock-in thermography. ECS Electrochemistry Letters, 2015. 4(9): p. A106-A109.

40. Engebretsen, E., et al., Electro-thermal impedance spectroscopy applied to an open-cathode polymer electrolyte fuel cell. Journal of Power Sources, 2016. 302: p. 210-214.

41. Bramble Energy makes progress on $5 \mathrm{~kW}$ air-cooled PCBFC stack. Fuel Cells Bulletin, 2018. 2018(2): p. 11-12.

42. Vollmer, M. and K.-P. Möllmann, Advanced methods in IR imaging, in Infrared Thermal Imaging. 2010, Wiley-VCH Verlag GmbH \& Co. KGaA. p. 157-237.

43. Bagavac, P., Lock-in thermography image processing. HDKBR INFO Magazin, 2016. 6(1): p. 3-7.

44. Chatterjee, K., et al., A comparison of the pulsed, lock-in and frequency modulated thermography nondestructive evaluation techniques. NDT \& E International, 2011. 44(7): p. 655-667.

45. Salazar, A., Energy propagation of thermal waves. European Journal of Physics, 2006. 27(6): p. 13491355.

46. Mulaveesala, R. and S. Tuli, Theory of frequency modulated thermal wave imaging for nondestructive subsurface defect detection. Applied Physics Letters, 2006. 89(19): p. 191913.

47. Subbarao, G.V. and R. Mulaveesala, Quadratic frequency modulated thermal wave imaging for nondestructive testing. Vol. 26. 2012. 11-22.

48. Breitenstein, O., W. Warta, and M. Langenkamp, Lock-in thermography: Basics and use for evaluating electronic devices and materials. 2010: Springer Berlin Heidelberg.

49. Morin, A., et al., Influence of PEMFC gas flow configuration on performance and water distribution studied by SANS: Evidence of the effect of gravity. International Journal of Hydrogen Energy, 2011. 36(4): p. 3096-3109.

50. Cho, J.I.S., et al., Capillaries for water management in polymer electrolyte membrane fuel cells. International Journal of Hydrogen Energy, 2018. 43(48): p. 21949-21958. 
51. Trogadas, P., et al., A lung-inspired approach to scalable and robust fuel cell design. Energy \& Environmental Science, 2018. 11(1): p. 136-143.

52. Clyde F. Coombs, Jr. and T.H. Happy, PCB design for thermal performance, in Printed Circuits Handbook, Seventh Edition. 2016, McGraw Hill Professional, Access Engineering. p. 483.

53. Tufnol. Whale Brand TUFNOL data sheet. 2017; Available from: http://docseurope.electrocomponents.com/webdocs/0725/0900766b807259ec.pdf.

54. Al-Obaidy, F., F. Yazdani, and F.A. Mohammadi, Intelligent testing for Arduino UNO based on thermal image. Computers \& Electrical Engineering, 2017. 58: p. 88-100.

55. Bär, J., A. Vshivkov, and O. Plekhov, Combined lock-in thermography and heat flow measurements for analysing heat dissipation during fatigue crack propagation. Vol. 9. 2015. 456-465.

56. Bär, J. and S. Seifert, Investigation of energy dissipation and plastic zone size during fatigure crack propagation in a high-alloyed steel. Procedia Materials Science, 2014. 3: p. 408-413.

57. Liu, B., et al., Quantitative evaluation of pulsed thermography, lock-in thermography and vibrothermography on foreign object defect (FOD) in CFRP. Sensors (Basel, Switzerland), 2016. 16(5): p. 743.

58. Maldague, X., Theory and practice of infrared technology for nondestructive testing /Xavier P. V. Maldague. 2001, New York, Chichester: Wiley.

59. Çengel, Y.A., Heat transfer: A practical approach. 2003: McGraw-Hill.

60. Coz, E., et al., Water management in a planar air-breathing fuel cell array using operando neutron imaging. Journal of Power Sources, 2016. 331: p. 535-543.

61. Cho, J.I.S., et al., Visualization of liquid water in a lung-inspired flow-field based polymer electrolyte membrane fuel cell via neutron radiography. Energy, 2019. 170: p. 14-21. 